\title{
The Influence of Smoking and Cessation on the Human Reproductive Hormonal Balance
}

\author{
H. JANDÍKOVÁ ${ }^{2}$, M. DUŠKOVÁ ${ }^{1}$, L. STÁRKA ${ }^{1}$ \\ ${ }^{1}$ Institute of Endocrinology, Prague, Czech Republic, ${ }^{2}$ Third Department of Medicine - Department \\ of Endocrinology and Metabolism, First Faculty of Medicine, Charles University and General \\ University Hospital in Prague, Prague, Czech Republic
}

Received April 1, 2017

Accepted May 29, 2017

\section{Summary}

Smoking is the most widespread substance dependence in the world. Nicotine and some other components of the cigarette smoke cause various endocrine imbalances, and have negative effects on pituitary, thyroid, adrenal, testicular and ovarian functions. Here, we examined studies that describe the influence of smoking and smoking cessation on the male and female reproductive systems. We also focused on studies providing an account of differences in cessation success rates between men and women. In men, the most common effects associated with smoking are erectile dysfunction and decreasing spermiogram quality. Several groups have studied the effects of cigarette smoking on testosterone levels in men. However, the results have been conflicting. In women, nicotine has an antiestrogen effect and increases the ratio of androgens to estrogens throughout life. Beside nicotine, other cigarette toxins also cause dysregulation of reproductive and hormonal system, and essentially influence the probability of a successful pregnancy not only in cases of assisted reproduction but also in healthy women. Tobacco addiction is one of the forms of addiction that are generally thought to be different for men and for women. Women are less successful than men in quitting smoking, and nicotine replacement therapy is less effective in female smokers. We also summarize recent studies that have indicated possible reasons.

\section{Key words}

Smoking • Steroids • Anti-estrogenic effect • Fertility

\section{Corresponding author}

H. Jandíková, Third Medical Department - First Faculty of Medicine, Charles University and General Faculty Hospital in Prague, U Nemocnice 1, 12808 Prague 2, Czech Republic. E-mail: hana.jandikova@vfn.cz

\section{Introduction}

Smoking is the most widespread addiction worldwide. Addiction to tobacco is a chronic, recurring and fatal illness. In both the Czech Republic and Europe as a whole, smoking is the cause of every fifth death, mainly through cancer, cardiovascular and chronic pulmonary diseases, but also affecting other diseases representing all clinical disciplines. Smoking causes 16,000 yearly deaths in the Czech Republic, and of those about 10,000 are people in their productive years (http://tobaccocontrol.bmj.com/content/suppl/2012/02/22/ tobaccocontrol-2011-050294.DC1/tobaccocontrol-2011050294-s1.pdf).

Tobacco smoke is a dynamic complex of more than 4000 volatiles and particles. It contains over 50 tumor-promoting carcinogens (for instance dibenzanthracene, benzo-[a]pyrene, dimethynitrosamine, diethylnitrosamine, vinylchloride, hydrazine, and arsenic) or suspected carcinogens (Hecht 1999). Other components include mutagens, allergens, toxic compounds, a high percentage of carbon monoxide, and about 700 additives. These affect a wide range of processes in the body including the secretion of hormones. 


\section{Smoking and the endocrine system}

Smoking influences hypophyseal, thyroid, adrenal, testicular and ovarian functions, calcium metabolism, and the activity of insulin (Stárka et al. 2005). In addition to nicotine, other toxins from cigarettes mediate the effects on hormonal secretions. For instance thiocyanate acts on the thyroid gland, with the main clinical effect being an increased risk and seriousness of Graves-Basedow toxicity (G-B toxicity) and endocrine orbitopathy, osteoporosis, and infertility. It also contributes to insulin resistance, and thus diabetes type 2 . Concerning the influence of smoking on the embryo, there are two important effects: smoking by the mother leads to increased catecholamine production, which causes a lower flow rate in the fetoplacental unit, and the effects of thiocyanate can lead to defects in the size and function of the embryonic thyroid gland (Kapoor and Jones 2005).

Smoking also alters the levels of endogenous steroid hormones. Both acute and chronic smoking increase plasma levels of cortisol, with cortisol levels correlating with the number of cigarettes smoked daily (Kirchbaum et al. 1992). Nicotine immediately activates the hypothalamic-hypophyseal-adrenocorticol axis (HPA). The cessation of smoking first leads to an increase in cortisol, but then a subsequent change in HPA activity and a dramatic decline in cortisol levels (Kirchbaum et al. 1992, Frederick et al. 1998). This decline, and the associated lowered sensitivity to stress, often predicts an imminent relapse. Declines in the ratio of dehydroepiandrostenedione (DHEA) to cortisol during the first eight days of quitting smoking have been associated with relapse in the following weeks (Rasmusson et al. 2006). Interestingly, this study demonstrated that the correlation between hormonal imbalance and relapse is only significant in men. In women, the prediction of relapse has rather been associated with the intensity of withdrawal symptoms (al'Absi 2006).

\section{The influence of smoking on the male reproductive system}

Chronic smoking can lead to fertility problems in both sexes. The most common effects associated with smoking are erectile dysfunction (Natali et al. 2005) and especially spermiogram quality (Trummer et al. 2002). There are inconsistent results in the literature on the effects of smoking on steroid hormone levels in men. In studies following changes in steroids due to smoking, both increases (Dai et al. 1988, Wang et al. 2013) and decreases (Shaarawy and Mahmoud 1982, Olayaki et al. 2008) have been reported, as well as data showing no effect of smoking on the total levels of testosterone (Barrett-Connor and Khaw 1987). These inconsistent results likely arise from multiple factors. One is the difficulty and non-standardization of laboratory methods. Another arises from not respecting the fact that testosterone levels vary during the day. Testosterone has a circadian rhythm with levels peaking between 6:00-8:00 and minimum concentrations between 18:00-20:00. An additional difficulty is that most studies on the effects of smoking on hormone levels do not discriminate between free and bound testosterone. There is a significant proportion of testosterone in the blood bound to SHBG (sex hormone-binding globulin) $(65-80 \%)$, with the remainder bound to albumin (20-40\%) or freely circulating (1-3\%).

The mechanism by which smoking can influence testosterone levels is not clear. One hypothesis considers that it is a secondary effect to changes in levels of SHBG in smokers. Most studies that have worked with SHBG levels agree that they are higher in smokers (English et al. 2001, Kapoor et al. 2005, Wang et al. 2013). At the same time there are also studies showing the opposite - lower testosterone levels as an influence of smoking. Some studies are based on experimental models. Mittler et al. (1983) followed the effects of chronic smoking on androgen metabolism in dogs, and showed lower activities of 7 alpha-hydroxylases and stimulated activities of hepatic 6 beta-hydroxylases. Serum levels of testosterone were lower and LH levels higher than in controls. These results indicate that chronic smoking increases the intra-hepatic metabolism of testosterone (Mittler et al. 1983). Patterson et al. (1990) showed that nicotine changes the steroidogenesis of Leydig cells in mice. Chronic doses of nicotine led to lower fertility in male rats. Nicotine also inhibits the pulse secretion of $\mathrm{LH}$ in rats, leading to the inhibition of LH-stimulated steroidogenesis (Patterson et al. 1990).

Human studies have confirmed this nicotine effect. Shaarawy and Mahmoud (1982) demonstrated significantly lowered levels of total testosterone in smokers versus non-smokers, but did not discriminate between levels of free, bioactive testosterone or SHBG levels. Other studies have shown lower concentrations of urinary testosterone in male smokers compared to age- 
and BMI-matched non-smokers (Olayaki et al. 2008).

Our group has studied the direct effects of quitting smoking, demonstrating the complex influence of smoking on hormone levels. We demonstrated that male smokers have lower levels of testosterone compared to non-smokers, and that these changes worsened after quitting smoking. Levels of testosterone continued to change for an entire year after cessation. In addition, there was a drop in SHBG, but already in the first week of non-smoking, and levels continued to remain low. Changes in SHBG and testosterone did not correlate with BMI (Hruškovičová et al. 2013).

\section{The influence of smoking on the female reproductive system}

The impact of cigarette smoking on reproductive organs and their function is mediated through a direct toxic effect, ovotoxicity (Mattison and Thorgeirsson 1978), as well as by influencing hormone secretion. The antiestrogenic effect of smoking could be explained by three potential mechanisms. The first mechanism is decreased activity of aromatases in granulosa cells and peripheral tissue and reduced C-20,22 desmolases activity with a subsequent reduction in steroid production in general (Ruan and Mueck 2015). In a study on the basic components of cigarette smoke, Osawa et al. identified tobacco alkaloid derivatives that had a suppressive effect on aromatase enzymes (Osawa et al. 1990).

Second explanation for the anti-estrogen effect is the strong effect of smoking on the 2-hydroxylation of estradiol metabolites that result in 2-hydroxyestrogens, irreversible metabolites that have minimal estrogenic activity and are quickly removed from circulation. This leads to a lower bio-availability of estrogen for sensitive tissues (Michnovicz et al. 1986, Quatrtrochi et al. 1994, Hankinson 1995, Meek and Finch 1999).

Third possibility has been demonstrated in rats, where diluted mainstream cigarette condensates are able to bind to the estrogen receptor and displace bound tritiated estradiol from the uterine estrogen receptor in a dose dependent manner. This binding also activates the estrogen receptor and might exert a subtle estrogenic effect, which might explain the contradictory results of several studies investigating the link between smoking and breast cancer (Meek and Finch 1999).

The effect of smoking on gonadotropins and steroids in women was investigated in a few studies, but most of the data are conflicting.

Thomas et al. (1993) demonstrated no major significant alterations in cyclicity (i.e. the length of the follicular or luteal phases), the secretion of gonadotropins, estradiol, and progesterone, the metabolism of estradiol, or the secretion of androgens in smoking women throughout the late follicular and luteal phases. On the other hand, a cohort study including premenopausal, smoking, and nonsmoking women from the BioCycle study showed significant, phase specific differences in hormone levels between smokers and non-smokers with higher levels of FSH in the early follicular phase and higher LH at menses in smokers compared with non-smokers (Whitcomb et al. 2010).

Compared to non-smoking women of reproductive age, smokers (slightly to heavy addicted, i.e. 10 or more cigarettes daily) have $25-35 \%$ increased estrogen and progesterone levels at the beginning of the follicular phase. Heavy smokers (20 or more cigarettes daily) have been shown to have lower progesterone metabolites in the luteal phase (Windham et al. 2005). The average plasma concentrations of androstenedione have been found to be higher in smokers versus non-smokers, but levels of testosterone, estrone, and estradiol were unchanged (Longcope and Johnston 1998). However, our own investigations have demonstrated that fertile women smokers have lower levels of estradiol, but only in the luteal phase (Duskova et al. 2012).

Data from the literature agree that smoking increases the levels of androgens at all stages of life. Martin et al. (2001) performed a pilot study focused on the relationships between testosterone levels, carbon monoxide, current smoking, and smoking during adolescence and the beginning of puberty in groups of young female smokers. Testosterone levels positively correlated with the number of cigarettes smoked in the prior 30 days, carbon monoxide levels, and smoking in the seventh and tenth grades of basic school, and negatively correlated with the age of onset of puberty (Martin et al. 2001). Manjer et al. (2005) showed that female smokers have a higher concentration of testosterone compared to non-smokers, and that the risk of this increase in fact rises with the number of cigarettes smoked per day. Sowers et al. (2001) performed an interesting study comparing steroid levels in pre- and perimenoupausal women and their lifestyles, age, and anthropomorphic characteristics. The highest testosterone levels were found in the smokers, followed by the ex-smokers and then non-smokers. Neither alcohol abuse, 
nor physical activity, nor dietary habits showed any association with testosterone levels, but testosterone levels were positively correlated with increasing BMI, weight, and proportion of fat in all women studied.

The same relationships have also been found in postmenopausal smokers, who have significantly higher testosterone levels compared to postmenopausal non-smokers (Friedman 1987).

Our group has demonstrated higher testosterone levels in fertile female smokers in both phases of their menstrual cycle (Duskova et al. 2012). Similarly, we have also found higher levels of androgens in smoking postmenopausal women (Jandikova et al. 2014). Our results indicate that smoking cessation in both premenopausal and postmenopausal women leads to further increases in androgens during the first year after quitting smoking (Duskova et al. 2010, Jandikova et al. 2014).

\section{Clinical consequences for women's reproductive health}

The consequences of the anti-estrogen effect of smoking are widespread. In heavy smoking women (more than 20 cigarettes daily), the follicular phase is shorter and irregular menstrual cycles are accentuated by the number of cigarettes smoked, which can lead to an increased risk of cycles with anovulation (Windham et al. 1999, Kato et al. 1999). In addition, smoking negatively influences the effect of hormonal birth control, leading to an increased incidence of spotting and bleeding in female smokers (Rosenberg et al. 1996). Smoking also causes more intense and more frequent menopausal problems (Staropoli et al. 1998). Although contradictory data have been published, most epidemiological studies have found an association between smoking and the risk of an earlier onset of menopause and reduced ovarian reserve (Dechanet et al. 2011, Freour et al. 2008).

Another serious complication of smoking is the influence on serum concentrations of estradiol and estrone when taking oral hormone substitution. Because of the anti-estrogen effect, there is a reduced positive effect from the substitution therapy (Tankó and Christiansen 2004). Smoking reduces the positive effects of hormonal substitution therapy used for hot flashes, climacteric syndrome, and urogenital disorders (Tansavatdi et al. 2004).

\section{Smoking and fertility in women}

Several studies have demonstrated a higher incidence of infertility in smokers. For instance, one study found that $21.3 \%$ of female smokers were still childless when reaching menopause compared to $14 \%$ for the general population (Thomford and Mattison 1986). Considering the outcomes of assisted reproductive technology, conflicting results have been reported. Some studies have shown that female smoking is associated with fewer oocytes (Barbieri et al. 2005), decreased rates of fertilization (Neal et al. 2005), fewer pregnancies (Pineles et al. 2014) and increased miscarriage rates (Meldrum et al. 2016). Studies of IVF have variously reported an increased gonadotropin requirement for ovarian stimulation, lower peak E2 levels, fewer oocytes retrieved, higher numbers of canceled cycles, lower implantation rates, and more cycles with failed fertilization in smokers compared to non-smokers (American Society for Reproductive Medicine 2006).

Interestingly, a study by Weigert et al. (1999) showed that in an IVF program smokers were significantly younger than non-smokers, and that they showed significantly lower scores for the vitality and development potential of embryos, as well as a tendency to produce fewer oocytes. However, there was not a significant difference between the number of normal and pathological fertilized transferred embryos or embryos suitable for cryopreservation (Weigert et al. 1999).

In contrast, other studies have reported no effect of smoking on fertilization and pregnancy rates. For example, a recent prospective study conducted by Cinar et al. (2014) did not find any significant difference in fertilization rates, transferred embryo quality, or clinical pregnancy rates when male and/or female smoking status was analyzed. Importantly, that study grouped patients as smokers and non-smokers based on their follicular or seminal fluid cotinine levels.

In animal models, nicotine has a negative effect on the ovaries and uterus of offspring, leading to ovarian dysfunction and increased serum progesterone levels and lower estrogen/progesterone ratios in female offspring (Holloway et al. 2006). Similarly, recent epidemiological studies have shown that maternal cigarette smoking is associated with impaired semen quality and decreased fertility rates in their female offspring (Hakonsen et al. 2014). 


\section{Nicotine addiction}

Addiction to tobacco has significant psychosocial aspects, but the basis of physical addiction is nicotine. Nicotine binds to acetylcholine-nicotine receptors and leads to the release of dopamine in brain tissues. Addiction can be very rapid, though there is individual variability. The half-life of nicotine is about two hours, so withdrawal symptoms can appear as soon as four hours after the last dose. These symptoms mainly include the urge to smoke, irritability, anxiety, difficulty concentrating, and restlessness increased after cessation. In addition, bradycardia, impatience, somatic complaints, insomnia, increased hunger, and increased eating occurred after cessation (Hughes and Hatsukami 1986).

In a study on acute subjective effects when giving nicotine intravenously, Sofuoglu and Mooney (2009) found interesting inter-gender differences. Groups of women and men were given doses of nicotine i.v. adjusted for their weights. Women assessed the doses as being more intense than did men, feeling a more intense rush to the head and greater negative effects. Men and women had similar reactions in lowering their urge to light a cigarette. There was also a similar increase in heart rate and blood pressure between the two sexes. These results demonstrate a higher sensitivity of women to some, though not all, of the subjective effects of nicotine.

Both estrogen and progesterone influence multiple reward-circuitry neurotransmitter systems (Lynch and Sofuoglu 2010). Estrogen has been shown in both preclinical and clinical research to increase the rewarding value of drugs of abuse including nicotine (Carroll et al. 2004, O'Dell and Torres 2014, Torres et al. 2009). Women also metabolize nicotine more quickly, especially women who are pregnant or taking oral contraceptives, suggesting a link to increased estrogen levels (Benowitz 2009, Benowitz et al. 2006). A relationship between estrogen and nicotine metabolism has important clinical implications because quicker nicotine metabolism is associated with more intense smoking (Strasser et al. 2011), a greater reward from nicotine (Sofuoglu et al. 2012), greater cravings to smoke after overnight smoking abstinence (Sofuoglu et al. 2012), and poorer cessation outcomes (Schnoll et al. 2009). Some studies suggest that estrogen may promote addictive behaviors through increased reward while progesterone may be protective against addictive behaviors through decreased reward value. For example, female rats demonstrate greater motivation for nicotine when progesterone levels are low and when there are greater estradiol levels relative to progesterone levels (Lynch 2009). Self-administration of nicotine decreases in female rats that are pregnant, a time when progesterone levels are high (Lesage et al. 2007).

\section{Differences in quitting smoking between sexes}

Tobacco addiction is one of the forms of addiction that are generally thought to be different for men and for women, and many studies have shown that women are less successful than men in quitting smoking (Pauly 2008, Duskova et al. 2010, Cosgrove et al. 2014). Even though social factors significantly influence smoking in humans, animal studies in controlled experiments support the fact that the sexual differences in nicotine addiction have a biological foundation (Pogun and Yararbas 2009). The current literature also indicates that nicotine therapy is less effective in female smokers. This could be due to an alteration in the pharmacokinetics of nicotine mediated by estrogen, or due to the fact that ovarian hormones act as non-competitive antagonists to nicotine receptors (Pauly 2008).

The stress response is regulated by two neuroendocrine systems. The first is the HPA axis, the activation of which can be measured using saliva cortisol as a marker. The second system is the sympaticoadrenergic, with saliva $\alpha$-amylase used as a marker. We measured levels of cortisol and $\alpha$-amylase in the saliva of men and women while quitting smoking, and showed that the men who were most successful in quitting had significantly higher levels of saliva $\alpha$-amylase during the entire period they were followed. At the same time, men who were unsuccessful had higher levels of saliva cortisol before quitting smoking. Similar results were not found for women. These results support the idea of a biological basis for differences in the success of quitting smoking between women and men (Duskova et al. 2010).

Psychosocial factors play important role in both sex, but probably more important for women and biological factors seem to be more crucial for addiction in men. A recent study by Cosgrove et al. (2014) using innovative PET imaging showed that male smokers activate dopamine in the right ventral striatum during smoking but that female smokers do not. This finding is consistent with the established notion that men smoke in order to reinforce the drug effect of cigarettes whereas women smoke for other reasons, such as mood regulation 
and cue reactivity.

Another recent study on women using a functional MRI during the presentation of neutral and smoking-related images known to elicit craving showed that the pattern of activation varied across their menstrual cycle, with significant activation in parts of the frontal, temporal, and parietal lobes during the follicular phase, and only limited activation in the right hippocampus during the luteal phase. These data indicate that incontrollable urges to smoke are stronger at the beginning of the follicular phase that begins after menstruation. Hormonal decreases of estrogen and progesterone possibly deepen the withdrawal syndrome and increase the activity of neural circuits associated with craving. Mendrek et al. (2014) proposed that it could therefore be easier for women to overcome abstinencerelated withdrawal symptoms during the mid-luteal phase, i.e. after ovulation, when their levels of estrogen and progesterone are elevated; however, psychosocial factors cannot be excluded.

The role of androgens in smoking addiction has been supported by studies on the influence of the mother smoking during pregnancy on addiction in their daughters. Interestingly, higher testosterone levels in mothers who smoked during pregnancy correlated with an increased incidence of their daughters' smoking, while prenatal cotinine levels did not. Thus, testosterone levels in maternal smokers is likely a risk factor in daughters' smoking (Kandel and Udry 1999).

In our studies, we have also shown that steroids and their neuroactive metabolites play an important role in smoking addiction as well as in quitting smoking. In prospective studies on male and female chronic smokers heavily addicted to tobacco, from the time of active smoking to up to one year of abstinence, we have collected unique data describing changes in the steroid metabolome. These changes were shown to be possible markers for predicting success in quitting smoking. For instance, hyperandrogenemia negatively correlates with success in quitting smoking in women, while lower testosterone levels in men predispose them to lower success in quitting smoking. It is interesting that the more androgens are impaired at the beginning and the more they change, the less likely it is that quitting smoking will be successful (Hruskovicova et al. 2013, Duskova et al. 2012).

\section{Conclusions}

Addiction to tobacco, diagnosis F17 in the international classification of diseases, is a serious psychosocial and economic problem. The negative effects of cigarette smoke exposure are complex, but they include the dysregulation of hormonal secretion and metabolism. The data in the literature are inconsistent, but epidemiologic studies worldwide have established that exposure to cigarette smoke is an important cause of estrogen deficiency. This has contributed to the increasing incidence of infertility, including changes to the ovarian response and quality of oocytes. Steroids and their neuroactive metabolites play an important role in smoking addiction as well as in quitting smoking. The results of some studies have indicated the potential use of serum concentrations of neuroactive steroids to predict success in quitting smoking.

\section{Conflict of Interest}

There is no conflict of interest.

\section{Acknowledgements}

The study was supported by the MEYS CR (OP RDE, Excellent research - ENDO.CZ), by $\mathrm{MH} \mathrm{CZ} \mathrm{-} \mathrm{DRO}$ (Institute of Endocrinology - EÚ, 00023761) and by grant GAUK 542216.

\section{References}

AL'ABSI M: Hypothalamic-pituitary-adrenocortical responses to psychological stress and risk for smoking relapse. Int J Psychophysiol 59: 218-227, 2006.

AMERICAN SOCIETY FOR REPRODUCTIVE MEDICINE: Smoking and infertility. Fertil Steril 86: 172-177, 2006.

BARBIERI RL, SLUSS PM, POWERS RD, MCSHANE PM, VITONIS A, GINSBURG E, CRAMER DC: Association of body mass index, age, and cigarette smoking with serum testosterone levels in cycling women undergoing in vitro fertilization. Fertil Steril 83: 302-308, 2005.

BARRETT-CONNOR E, KHAW KT: Cigarette smoking and increased endogenous estrogen levels in men. Am $J$ Epidemiol 126: 187-192, 1987.

BENOWITZ NL: Pharmacology of nicotine: addiction, smoking-induced disease, and therapeutics. Annu Rev Pharmacol Toxicol 49: 57-71, 2009. 
BENOWITZ NL, LESSOV-SCHLAGGAR CN, SWAN GE, JACOB P 3RD: Female sex and oral contraceptive use accelerate nicotine metabolism. Clin Pharmacol Ther 79: 480-488, 2006.

CARROLL ME, LYNCH WJ, ROTH ME, MORGAN AD, COSGROVE KP: Sex and estrogen influence drug abuse. Trends Pharmacol Sci 25: 273-279, 2004.

CINAR O, DILBAZ S, TERZIOGLU F, KARAHALIL B, YÜCEL C, TURK R, TASKIN L, KOSE SK: Does cigarette smoking really have detrimental effects on outcomes of IVF? Eur J Obstet Gynecol Reprod Biol 174: 106-110, 2014.

COSGROVE KP, WANG S, KIM SJ, MCGOVERN E, NABULSI N, GAO H, LABAREE D, TAGARE HD, SULLIVAN JM, MORRIS ED: Sex differences in the brain's dopamine signature of cigarette smoking. J Neurosci 34: 16851-16855, 2014.

DAI WS, GUTAI JP, KULLER LH, CAULEY JA: Cigarette smoking and serum sex hormones in men. $A m \mathrm{~J}$ Epidemiol 128: 796-805, 1988.

DECHANET C, ANAHORY T, MATHIEU DAUDE JC, QUANTIN X, REYFTMANN L, HAMAMAH S, HEDON B, DECHAUD H: Effects of cigarette smoking on reproduction. Hum Reprod Update 17: 76-95, 2011.

DUSKOVA M, SIMUNKOVA K, HILL M, HRUSKOVICOVA H, HOSKOVCOVA P, KRALIKOVA E, STARKA L: Higher levels of salivary alpha-amylase predict failure of cessation efforts in male smokers. Physiol Res 59: 765-771, 2010.

DUŠKOVÁ M, SIMŮNKOVÁ K, HILL M, VELÍKOVÁ M, KUBÁTOVÁ J, KANCHEVA L, KAZIHNITKOVÁ H, HRUŠKOVIČOVÁ H, POSPÍŠILOVÁ H, RÁCZ B, SALÁTOVÁ M, CIRMANOVÁ V, KRÁLÍKOVÁ E, STÁRKA L, PAŘÍZEK A: Chronic cigarette smoking alters circulating sex hormones and neuroactive steroids in premenopausal women. Physiol Res 61: 97-111, 2012.

ENGLISH KM, PUGH PJ, PARRY H, SCUTT NE, CHANNER KS, JONES TH: Effect of cigarette smoking on levels of bioavailable testosterone in healthy men. Clin Sci (Lond) 100: 661-665, 2001.

FREDERICK SL, REUS VI, GINSBERG D, HALL SM, MUNOZ RF, ELLMAN G: Cortisol and response to dexamethasone as predictors of withdrawal distress and abstinence success in smokers. Biol Psychiatry 43: 525-530, 1998.

FREOUR T, MASSON D, MIRALLIE S, JEAN M, BACH K, DEJOIE T, BARRIERE P: Active smoking compromises IVF outcome and affects ovarian reserve. Reprod Biomed Online 16: 96-102, 2008.

FRIEDMAN AJ, RAVNIKAR VA, BARBIERI RL: Serum steroid hormone profiles in postmenopausal smokers and nonsmokers. Fertil Steril 47: 398-401, 1987.

HAKONSEN LB, ERNST A, RAMLAU-HANSEN CH: Maternal cigarette smoking during pregnancy and reproductive health in children: a review of epidemiological studies. Asian J Androl 16: 39-49, 2014.

HANKINSON O: The aryl hydrocarbon receptor complex. Annu Rev Pharmacol Toxicol 5: 307-340, 1995.

HECHT S: Tobacco smoke carcinogens and lung cancer. J Natl Cancer Inst 14: 1194-1210, 1999.

HOLLOWAY AC, KELLENBERGER LD, PETRIK JJ: Fetal and neonatal exposure to nicotine disrupts ovarian function and fertility in adult female rats. Endocrine 30: 213-216, 2006.

HRUŠKOVIČOVÁ H, DUŠKOVÁ M, ŠIMU゚NKOVÁ K, HILL M, POSPÍŠILOVÁ H, RÁCZ B, KRÁLÍKOVÁ E, VONDRA K, STÁRKA L: Effects of smoking cessation on hormonal levels in men. Physiol Res 62: 67-73, 2013.

HUGHES JR, HATSUKAMI D: Signs and symptoms of tobacco withdrawal. Arch Gen Psychiatry 43: 289-294, 1986.

JANDÍKOVÁ H, DUŠKOVÁ M, ŠIMŮNKOVÁ K, RÁCZ B, HILL M, POSPÍŠILOVÁ H, KMEŤOVÁ A, KRÁLÍKOVÁ E, VONDRA K, STÁRKA L: How smoking cessation influence hormonal levels in postmenopausal women? Prague Med Rep 115: 60-66, 2014.

KANDEL DB, UDRY JR: Prenatal maternal effects of smoking on daughters' smoking: nicotine or testosterone exposure? Am J Public Health 89: 1377-1383, 1999.

KAPOOR D, JONES TH: Smoking and hormones in health and endocrine disorders. Eur J Endocrinol 152: 491-499, 2005.

KATO I, TONIOLO P, KOENIG KL, SHORE RE, ZELENIUCH-JACQUOTTE A, AKHMEDKHANOV A, RIBOLI E: Epidemiologic correlates with menstrual cycle length in middle aged women. Eur J Epidemiol 15: 809-814, 1999. 
KIRSCHBAUM C, WÜST S, STRASBURGER CJ: 'Normal' cigarette smoking increases free cortisol in habitual smokers. Life Sci 50: 435-442, 1992.

LESAGE MG, KEYLER DE, BURROUGHS D, PENTEL PR: Effects of pregnancy on nicotine self-administration and nicotine pharmacokinetics in rats. Psychopharmacology (Berl) 194: 413-421, 2007.

LONGCOPE C, JOHNSTON CC JR: Androgen and estrogen dynamics in pre- and postmenopausal women: a comparison between smokers and nonsmokers. J Clin Endocrinol Metab 67: 379-383, 1988.

LYNCH WJ: Sex and ovarian hormones influence vulnerability and motivation for nicotine during adolescence in rats. Pharmacol Biochem Behav 94: 43-50, 2009.

LYNCH WJ, SOFUOGLU M: Role of progesterone in nicotine addiction: evidence from initiation to relapse. Exp Clin Psychopharmacol 18: 451-461, 2010.

MANJER J, JOHANSSON R, LENNER P: Smoking as a determinant for plasma levels of testosterone, androstenedione, and DHEAs in postmenopausal women. Eur J Epidemiol 20: 331-337, 2005.

MARTIN CA, LOGAN TK, PORTIS C, LEUKEFELD CG, LYNAM D, STATON M, BROGLI B, FLORY K, CLAYTON RR: The association of testosterone with nicotine use in young adult females. Addict Behav 26: 279-283, 2001.

MEEK MD, FINCH GL: Diluted mainstream cigarette smoke condensates activate estrogen receptor and aryl hydrocarbon receptor mediated gene transcription. Environ Res 80: 9-17, 1999.

MELDRUM DR, CASPER RF, DIEZ-JUAN A, SIMON C, DOMAR AD, FRYDMAN R: Aging and the environment affect gamete and embryo potential: can we intervene? Fertil Steril 105: 548-559, 2016.

MENDREK A, DINH-WILLIAMS L, BOURQUE J, POTVIN S: Sex differences and menstrual cycle phase-dependent modulation of craving for cigarette: an FMRI pilot study. Psychiatry $J$ 2014: 723632, 2014.

MICHNOVICZ JJ, HERSHCOPF RJ, NAGANUMA H, BRADLOW HL, FISHMAN J: Increased 2-hydroxylation of estradiol as a possible mechanism for the antiestrogenic effect on cigarette smoking. $N$ Engl J Med 315: 1305-1309, 1986.

MITTLER JC, POGACH L, ERTEL NH: Effects of chronic smoking on testosterone metabolism in dogs. $J$ Steroid Biochem 18: 759-763, 1983.

NATALI A, MONDAINI N, LOMBARDI G, DEL POPOLO G, RIZZO M: Heavy smoking is an important risk factor for erectile dysfunction in young men. Int J Impot Res 17: 227-230, 2005.

NEAL MS, HUGHES EG, HOLLOWAY AC, FOSTER WG: Sidestream smoking is equally as damaging as mainstream smoking on IVF outcomes. Hum Reprod 20: 2531-2535, 2005.

O'DELL LE, TORRES OV: A mechanistic hypothesis of the factors that enhance vulnerability to nicotine use in females. Neuropharmacology 76: 566-580, 2014.

OLAYAKI LA, EDEOJA EO, JIMOH OR, GHAZAL OK, OLAWEPO A, JIMOH AG, BILIAMINU SA: Effects of cigarette smoking on urinary testosterone excretion in men. Biokemistri 20: 29-32, 2008.

OSAWA Y, TOCHIGI B, TOCHIGI M, OHNISHI S, WATANABE Y, BULLION K, OSAWA G, NAKABAYASHI Y, YARBOROUGH C: Aromatase inhibitors in cigarette smoke, tobacco leaves and other plants. $J$ Enzyme Inhib 4: 187-200, 1990.

PATTERSON TR, STRINGHAM JD, MEIKLE AW: Nicotine and cotinine inhibit steroidogenesis in mouse Leydig cells. Life Sci 46: 265-272, 1990.

PAULY JR: Gender differences in tobacco smoking dynamics and the neuropharmacological actions of nicotine. Front Biosci 13: 505-516, 2008.

PINELES BL, PARK E, SAMET JM: Systematic review and meta-analysis of miscarriage and maternal exposure to tobacco smoke during pregnancy. Am J Epidemiol 179: 807-823, 2014.

POGUN S, YARARBAS G: Sex differences in nicotine action. Handb Exp Pharmacol 192: 261-291, 2009.

QUATRTROCHI LC, VU T, TUKEY RH: The human CYP1A1 gene and induction by 3-methylchlorantrene: a region of DNA that supports AH receptor binding and promotor specific binding. J Biol Chem 269: 6949-6954, 1994.

RASMUSSON AM, WU R, PALIWAL P, ANDERSON GM, KRISHNAN-SARIN S: A decrease in the plasma DHEA to cortisol ratio during smoking abstinence may predict relapse: a preliminary study. Psychopharmacology (Berl) 186: 473-480, 2006. 
ROSENBERG MJ, WAUGH MS, STEVENS CM: Smoking and cycle control among oral contraceptive users. Am $J$ Obstet Gynecol 174: 628-632, 1996.

RUAN X, MUECK AO: Impact of smoking on estrogenic efficacy. Climacteric 18: 38-46, 2015.

SCHNOLL RA, PATTERSON F, WILEYTO EP, TYNDALE RF, BENOWITZ N, LERMAN C: Nicotine metabolic rate predicts successful smoking cessation with transdermal nicotine: a validation study. Pharmacol Biochem Behav 92: 6-11, 2009.

SHAARAWY M, MAHMOUD KZ: Endocrine profile and semen characteristics in male smokers. Fertil Steril 38: 255-257, 1982.

SOFUOGLU M, MOONEY M: Subjective responses to intravenous nicotine: greater sensitivity in women than in men. Exp Clin Psychopharmacol 17: 63-69, 2009.

SOFUOGLU M, HERMAN AI, NADIM H, JATLOW P: Rapid nicotine clearance is associated with greater reward and heart rate increases from intravenous nicotine. Neuropsychopharmacology 37: 1509-1516, 2012.

SOWERS MF, BEEBE JL, MCCONNELL D, RANDOLPH J, JANNAUSCH M: Testosterone concentrations in women aged 25-50 years: associations with lifestyle, body composition, and ovarian status. Am J Epidemiol 153: 256-264, 2001.

STÁRKA L, HILL M, KRÁLÍKOVÁ E: Smoking and endocrine system (in Czech). DMEV 8: 180-186, 2005.

STAROPOLI CA, FLAWS JA, BUSH TL, MOULTON AW: Predictors of menopausal hot flashes. $J$ Womens Health 7: 1149-1155, 1998.

STRASSER AA, BENOWITZ NL, PINTO AG, TANG KZ, HECHT SS, CARMELLA SG, TYNDALE RF, LERMAN CE: Nicotine metabolite ratio predicts smoking topography and carcinogen biomarker level. Cancer Epidemiol Biomarkers Prev 20: 234-238, 2011.

TANKÓ LB, CHRISTIANSEN C: An update on the antiestrogenic effect of smoking: a literature review with implications for researchers and practitioners. Menopause 11: 104-109, 2004.

TANSAVATDI K, MCCLAIN B, HERRINGTON DM: The effects of smoking on estradiol metabolism. Minerva Ginecol 56: 105-114, 2004.

THOMAS EJ, EDRIDGE W, WEDDELL A, MCGILL A, MCGARRIGLE HH: The impact of cigarette smoking on the plasma concentration of gonadotropins, ovarian steroids and androgens and upon the metabolism of estrogens in the human female. Hum Reprod 8: 1187-1193, 1993.

THOMFORD PJ, MATTISON DR: The effect of cigarette smoking on female reproduction. $J$ Ark Med Soc 82: 597-604, 1986.

TORRES OV, NATIVIDAD LA, TEJEDA HA, VAN WEELDEN SA, O'DELL LE: Female rats display dosedependent differences to the rewarding and aversive effects of nicotine in an age-, hormone-, and sexdependent manner. Psychopharmacology (Berl) 206: 303-312, 2009.

TRUMMER H, HABERMANN H, HAAS J, PUMMER K: The impact of cigarette smoking on human semen parameters and hormones. Hum Reprod 17: 1554-1559, 2002.

WANG W, YANG X, LIANG J, LIAO M, ZHANG H, QIN X, MO L, LV W, MO Z: Cigarette smoking has a positive and independent effect on testosterone levels. Hormones (Athens) 12: 1-10, 2013.

WEIGERT M, HOFSTETTER G, KAIPL D, GOTTLICH H, KRISCHKER U, BICHLER K, POEHL M, FEICHTINGER W: The effect of smoking on oocyte quality and hormonal parameters of patients undergoing in vitro fertilization-embryo transfer. $J$ Assist Reprod Genet 16: 287-293, 1999.

WHITCOMB BW, BODACH SD, MUMFORD SL, PERKINS NJ, TREVISAN M, WACTAWSKI-WENDE J, LIU A, SCHISTERMAN EF: Ovarian function and cigarette smoking in the Biocycle study. Paediatr Perinat Epidemiol 24: 433-440, 2010.

WINDHAM GC, ELKIN EP, SWAN SH, WALLER KO, FENSTER L: Cigarette smoking and effects on menstrual function. Obstet Gynecol 93: 59-65, 1999.

WINDHAM GC, MITCHELL P, ANDERSON M, LASLEY BL: Cigarette smoking and effects on hormone function in premenopausal women. Environ Health Perspect 113: 1285-1290, 2005. 